\title{
Disorientation and Vertigo
}

SE CTIONS I (Physiology) and J (Psychology) of the British Association discussed on September 7 at a joint meeting the problems of disorientation and vertigo. Dr. J. T. MacCurdy (Cambridge) was the first speaker. He said that the most universal type of physiological orientation is the reaction to gravity. When the effective value of $g$ is varied, there is an increase or decrease in the tension of the muscles which withstand the drag. When the direction of $g$ is changed, there are reflex movements of the trunks and limbs which re-orient the body to $g$, the so-called righting reflexes. Any disturbance of these balancing reactions would upset the bodily orientation, if there were no accessory means of judging the direction of $g$. Such a means exists in vision.

The labyrinthine sensations, regarded generally as the most important for maintaining posture, are regarded by MacCurdy, following Garten, as the least important, and the muscle and deep pressure senses as the most important factors.

Discussing the relationship of vertigo to disorientation, Dr. MacCurdy pointed out that when the labyrinth or other parts of the balancing system are diseased, the body is physiologically disoriented, but the individual is not necessarily psychologically disoriented, if his judgment remains intact. His judgment, however, can be interfered with in three ways : either his attention may be distracted by giddiness or by his efforts to maintain his balance; or objects themselves may be viewed with difficulty because they are in motion or seen at an unfamiliar angle; or the posture-balance component of the visual perception may be absent or distorted. All these conditions involve for compensation the intellectual building up of a correct perception, which may be substituted for the usual, automatically correct reaction to $g$.

Dr. MacCurdy illustrated his points from the sphere of flying, and further illustrations were given by Flight-Lieutenant Haslam, R.A.F.

In his final remarks, MacCurdy discussed nausea and vomiting and formulated a theory as to its physiological mechanism. Two types of sensitiveness probably exist, he suggested, one due to violent changes in the value of $g$, the other due to changes in the direction of $g$. The normal response to increase of $g$ is tension in the extensors and rigidity of the abdominal walls. If this is ineffective, a diaphragmatic tug ensues. Dr. T. G. Maitland (Cunard Steamship Co., Ltd.) agreed that the diaphragmatic pull is important, but only as an auxiliary cause of nausea.

Dr. Maitland pointed out that the vestibule and the semi-circular canals are the chief receptors of imposed movement. They have been evolved to meet only certain modes of such movement. When they encounter movements of another order, the reflexes they evoke not only fail to maintain equilibrium, but also actually disturb it. The sensory receptors of the muscles, tendons and joints, and the skin of the supporting structures, are excited by these reflexes. These muscles give a false orientation and so vertigo is caused which is an 'emotive and hallucinatory reaction'. Vertigo, of course, may also arise from other causes.

It is not certain what part the semicircular canals, primarily receptors for rotatory movement, play in rectilinear movement, though both rotatory and rectilinear movements excite vertigo. Although evidence from experiments is conflicting, various facts suggest that rectilinear movements do affect the semi-circular canals, but not when the deviation is stight. Dr. Maitland also directed attention to the fact that the conditions of the vertigo excited by descending rectilinear movement are the reverse of those of the vertigo excited by angular rotatory movement. In the former case, the vertigo is pronounced at the inception of the movement, reaches its maximum with acceleration, diminishes with retardation, and disappears with cessation; whereas in the latter case, it is absent at the inception or acceleration of the movement, slight with retardation, and maximal with cessation.

Squadron-Leader E. D. Dickson, R.A.F., remarked that controversy has raged over the part played in flying by the vestibular apparatus, and that played by deep sensibility and eyesight in appreciating the position and movement of the aeroplane in space. In movements such as loops, spins, nose-dives, etc., the manœuvre is undoubtedly appreciated by the nerve-endings in the semi-circular canals and to some extent by the otoliths, but this does not mean that consciousness is necessarily involved. In movements concerned with inclinations round a sagittal axis, such as in banking, or rising or descending, it is difficult to determine what part is played by the labyrinth and deep sensibility, and what part is played by perception of the position of the aeroplane in space. He then proceeded to discuss in detail the various evolutions practised in flying and to analyse very carefully the salient features in each. His general conclusions were: (1) the labyrinth plays no definite rôle in orientation so far as flying is concerned; (2) sight is the most important factor in informing us of our position in space; (3) in the absence of sight, deep sensibility is next in importance.

Mr. R. J. Bartlett (King's College, London) took up the position that probably one immediate physiological cause of disorientation and vertigo is insufficiency of available oxygen in the blood supply to the brain. Faulty breathing may, therefore, be a causative factor. In air and water travel, a principal cause of the faulty breathing may be the bodily reactions to the changing incidence of the pull of gravity with the rolling or pitching of boat or aeroplane. Bartlett finds that the effects of land and ocean travel can be induced in suitable subjects by vibration without any rolling, pitching or translatory movement. The subject sits in a chair attached to a box containing a motor loaded eccentrically and run at speeds from twelve to twenty revolutions per second. Changes in the frequency of the vibration and certain critical frequencies are found to be particularly effective; pneumograph records show the marked effect on the breathing of susceptible subjects. When it is difficult or impossible to keep the vibration and the breathing in harmony, discomfort is experienced.

Dr. R. S. Creed (Oxford) stated that in vertigo there must be : (1) false sensations of movement, or perhaps sometimes only of position; (2) a tendency to make compensatory movements jeopardising balance; and (3) consciousness of the falsity of the sensations, causing a feeling of uncertainty and unsafeness whence arises mental confusion and distress. The first two of these may occur alone, resulting in some degree of disorientation, and the subject may fall to the 
ground, but without any of the unpleasant feelings associated with the word giddiness.

In people who are particularly susceptible, vertigo accompanied even by nausea and vomiting may easily be brought about by kinæsthetic impulses or by moving visual stimuli. But that the labyrinth is by far the most usual and important sense organ from which vertigo is aroused, and probably the only one concerned in sea-sickness, is now firmly established. James, Kreidl and Myginol have all commented on the immunity from sea-sickness of deafmutes in whom the labyrinths were deficient. The experiments of Dreyfuss on guinea-pigs and of
Kreidl on dogs, cats and pigeons pointed in the same direction. Decerebration, decerebellation, or section of both vagi leaves sea-sickness unaffected, but removal of both labyrinths or section of both eighth nerves results in complete immunity. The most likely explanation of the vomiting seems to be that it is caused by spread of excitation from the vestibular nuclei to the neighbouring medullary 'vomiting centre'.

As a result of the interest aroused in the discussion, a joint research committee of the Sections of Physiology and Psychology has been set up to investigate the conditions of vertigo and its relation to dis. orientation.

\section{Fishes of Mountain Streams}

$\mathrm{D}^{\mathrm{R}}$ R. SUNDER LAL HORA, of the Zoological Survey of India, has for many years devoted special attention to the study of the fauna of rapidly running waters in the hill streams of India. His knowledge of this difficult and interesting branch of zoology is unrivalled. No one, therefore, could be better qualified than he to undertake a detailed investigation* of that remarkable group of cyprinoid fishes, the Homalopteridæ. These fishes, inhabitants of swiftly running mountain streams of southern Asia, have undergone a great variety of adaptive modifications induced by the peculiar environmental conditions typical of their habitat.

In the first part of his report the author deals with the taxonomy of the group. It is divided into 2 sub-families-the Homalopterinæ, comprising 6 genera and 31 species, and the Gastromyzoninæ which is represented by 11 genera having in all about 16 species. In the Homalopterinæ 4 new species belonging to the genera Homaloptera and Lepturichthys, and 2 new varieties of Balitora brucei are described. Among the Gastromyzoninæ no new species have been found; but in order properly to classify the existing species 5 new genera are proposed in this paper. No attempt has been made to describe in full each and every species, but wherever an amplification of the already existing description seemed to the author to be desirable the species is

* Memoirs of the Indian Museum, vol. 12, No. 2, pp. 263-330. "Classifleation, Bionomics and Evolution of Homalopterid Fishes". By Sunder Lal Hora. Calcutta ; December, 1932. either redescribed or a note is inserted concerning some of its most important features.

In the second part of the paper the bionomies and evolution of the Homalopteridæ are discussed at some length. The most characteristic features of its members such as flattened shape, insertion of the pectoral fins (which are used for adhesion) far forward below or even in front of the eyes, possession of a peculiar rostral groove in front of and continued along each side of the mouth, the peculiar structure of the hard and strong lower jaw, are shown to be definitely correlated with the three most important factors in the environment-strong current, high oxygen content, and nature of the food supply available. Throughout the paper attention is repeatedly directed to the 'communal convergence' that is exhibited by these fishes and to the series of characters showing parallel development in the members of the two sub-families. From all the evidence which he has acquired the author believes that the Homalopteridæ are probably a polyphyletic family the members of which are derived from the Cyprinidæe and Cobitidæ and have come to resemble one another superficially under the influence of the same environmental conditions.

Dr. Hora is to be congratulated on having produced a paper which is not only a valuable addition to the literature on the taxonomy of the Homalopteridæ but is also of great theoretical interest.

G. A. S.

\section{Geological Reconnaissance by Aeroplane in Australia*}

$I^{\mathrm{N}}$ 1932 the Royal Australian Air Force made flights over many of those areas in Australia which are deemed to be worthy of investigation from the point of view of the discovery of oil. Dr. W. G. Woolnough, who was present as observer and geologist, has now detailed the results obtained in a report which gives valuable information regarding the function and importance of aerial work in assisting and expediting geological survey. The object was to determine the disposition of strata and especially to locate dome structures, the investigation being made partly by visual observation and partly by the study of the photographs taken from the air. Much experience is required before the utmost can be achieved by these methods, and Dr. Woolnough states that he scarcely began to appreciate the significance of details seen from above until he had completed one hundred hours of flying.

* Commonwealth of Australia. Report on Aerial Survey Operations In Australia during 1932. By Dr. W. G. Woolnough. (Canberra: Government Printers.)
From July until September, a circuit of Australia was made-also a visit to Tasmania, atmospheric conditions on the whole being favourable. Over Melville Island observation was hindered by a tribal fight, as part of the strategy consisted in the lighting of extensive bush fires, the smoke of which provided nuclei for the condensation of moisture and the development of clouds. The orientation of the photographs and the elevation of hills and scarps above the surrounding country can be determined by noting the direction and lengths of shadowsprovided the time of exposure is accurately known.

In those regions where the rocks are well exposed and where topographical forms are the direct result of the differential erosion of beds, the main tectonic features are easily seen, and examination of the photographs reveals where the detailed ground investigation which is essential to the full elucidation of the structure should be undertaken. Most valuable is the clearness with which the true disposition and 